\title{
CULTURA ORGANIZACIONAL COMO FATOR COMPLEMENTAR ÀS DIMENSÕES CULTURAIS DE HOFSTEDE
}

\author{
ORGANIZATIONAL CULTURE AS A SUPLEMENTARY FACTOR OF HOFSTEDE'S CULTURAL \\ DIMENSIONS
}

Rodrigo Moreira Casagrande *

Doutorando em Administração na Fundação Universidade de Blumenau - FURB

Blumenau, SC, Brasil

E-mail: rodrigomcasagrande2013@gmail.com

Denise Del Prá Netto Machado

Professora Doutora do Programa de Doutorado em Contabilidade e Administração da FURB

Blumenau, SC, Brasil

E-mail: profadenisedelpra@gmail.com

\section{RESUMO}

Partindo do pressuposto de que a cultura organizacional gera expectativas quanto a comportamentos nas organizações, a temática deste trabalho enquadra-se no campo de estudo de gestão de pessoas e apresenta uma abordagem teóricoempírica que tem o objetivo de analisar eventuais fragilidades teóricas causadas pela negligência do impacto da cultura organizacional na composição das dimensões culturais de Hofstede. Utilizou-se como metodologia uma análise descritiva com base nos resultados obtidos em estudos realizados em três organizações: uma cooperativa de crédito, um banco e um hospital. Os resultados sugerem que, na medida em que a cultura organizacional de um determinado setor gera entendimentos partilhados e um senso comum que influencia os comportamentos no ambiente organizacional, deve ser considerada de forma complementar à abordagem das dimensões culturais de Hofstede, a qual não observa este aspecto nas suas proposições.

Palavras-chave: Dimensões culturais de Hofstede. Comportamento humano. Cultura organizacional. Cultura nacional.

\section{ABSTRACT}

Assuming that the organizational culture generates expectations of behavior in organizations, the theme of this work is part of the field of study of human resources management and presents a theoretical and empirical approach that aims to analyze possible theoretical weaknesses caused by the negligence of the impact of organizational culture on the composition of the Hofstede's cultural dimensions. The research method involves a descriptive analysis based on the results obtained in studies of three organizations: a financial cooperative, a bank and a hospital. The results suggest that organizational culture of a particular industry generates shared understanding and a common sense that influences the behaviors in the organizational environment. Therefore, organizational culture should be considered in Hofstede's cultural dimensions, which does not observe this aspect in their propositions.

Keywords: Hofstede's cultural dimensions. Human behavior. Organizational culture. National culture. 


\section{INTRODUÇÃO}

A cultura, no campo organizacional, exerce um papel de balizamento do comportamento humano, por meio do universo simbólico, que gera uma construção social da realidade, e do racionalismo funcional, que faz com que práticas sejam "dadas como certo". Schein (2009), discorre sobre a influência que artefatos, crenças e valores expostos geram nas atitudes das pessoas que compõem as organizações.

A cultura organizacional define fronteiras, criando diferenciações entre uma organização e outra, e também proporciona um senso de identidade aos seus membros, funcionando como uma espécie de argamassa social que mantém a organização coesa, sinalizando padrões adequados de comportamento (O’REILLY et al., 1996).

Hofstede (1991, 2001), em sua pesquisa realizada em unidades da IBM, em 53 países, conseguiu interligar valores culturais com indexadores numéricos que produzem comparações entre nações, além de enfatizar valores culturais que podem ser encontrados nos ambientes de trabalho. $\mathrm{O}$ autor identificou, em seus trabalhos pioneiros, quatro dimensões de valores, quais sejam: distância hierárquica, individualismo versus coletivismo, masculinidade versus feminilidade e controle da incerteza (HOFSTEDE, 1991, 2001).

O foco da abordagem de Hofstede $(1980,1991,2001)$ envolve diferenças transculturais entre países distintos, enfatizando a cultura nacional. Morgan (1996) considera que as diferenças transculturais não devem ser subestimadas no estudo da cultura organizacional. Porém, destaca uma questão relevante para este artigo, quando desvia um pouco o foco da cultura transnacional e aborda que "muitas das principais semelhanças e diferenças culturais no mundo de hoje são mais ocupacionais do que nacionais" (MORGAN, 1996, p. 117).

Nesse contexto, a questão de pesquisa é: por que a cultura organizacional deve ser considerada de forma complementar às dimensões culturais de Hofstede? O objetivo do trabalho é analisar a possibilidade do surgimento de eventuais fragilidades no estudo das dimensões de Hofstede (1991, 2001) que atua num plano de cultura nacional, ao subestimar o impacto da cultura organizacional enquanto indutora de comportamentos.

O trabalho mostra-se relevante, dado que a pesquisa transnacional de Hofstede (1991, 2001), que se tornou um se tornou um paradigma para a comparação de culturas, foi aplicada no início da década de 1970, e, por isso, talvez seja pertinente analisar a cultura com a inserção de outras variáveis. No caso desta pesquisa, a utilização de organizações com atividades distintas, localizadas em um mesmo país. 


\section{APORTES TEÓRICOS}

Esta seção se propõe a apresentar aspectos conceituais da cultura organizacional e das dimensões culturais de Hofstede.

\section{Cultura Organizacional}

A temática cultura organizacional consolidou-se na academia a partir de 1983, quando foram publicadas edições especiais sobre o tema nos periódicos Administrativa Science Quarterly e Organizational Dynamics. A literatura levantada sobre cultura organizacional coloca luz na questão da identidade da organização, na medida em que representa um sistema de valores compartilhados pelos membros de uma organização e que pode thes diferenciar das demais (SCHEIN, 2009; BECKER, 1982).

Nas pesquisas sobre cultura organizacional o autor mais citado é Edgar Schein, que define cultura como sendo a adoção de comportamentos relacionados à solução dos problemas externos e internos que funcionaram consistentemente para o grupo. Por conta disso, passam a ser ensinados aos novos membros como o modo correto de perceber, pensar e sentir em relação a esses problemas (SCHEIN, 2009).

Além do aspecto do compartilhamento, a cultura organizacional também implica algum nível de estabilidade estrutural no grupo, gerando uma sensação de estabilidade (SCHEIN, 2009). Essa sensação gera um bem-estar ocasionado pela diminuição de opções na escolha da forma como se comportar, uma vez que já existe um "dado como certo" gerador de significado e previsibilidade (SCOTT; CHRISTENSEN, 1995). É o que Robbins (2002) definiu como permanência institucional, quando os modos de comportamento aceitáveis se tornam fortemente auto-evidenciados para seus membros.

Tal abordagem encontra amparo na abordagem de Selznick (1948), que alega que a institucionalização organizacional representa a conquista por parte da empresa de uma vida própria, independente dos fundadores e de determinados membros da organização. Desta maneira, cada empresa tem uma personalidade coletiva que transparece na forma como as pessoas nela trabalham e se relacionam, tomam decisões, se comunicam (inclusive com jargões), mantêm tabus e preconceitos. Esse compartilhamento de costumes, crenças e ideias pré-estabelecidas geram modelos mentais que funcionam como uma espécie de mapa, um modo de interpretar e agir perante o mundo (JOHANN, 2013).

É fato que as pessoas têm uma vida social anterior à adesão a uma organização empresarial. $\mathrm{Na}$ medida em que o comportamento humano resulta de manifestações culturais do passado e do presente e o passado influencia reiteradamente o presente, o convívio no ambiente organizacional de pessoas de diferentes culturas tende a gerar implicações por conta de estereótipos, preconceitos, diferenças de linguagem e interpretações da realidade (WREN, 2007). Berger e Luckmann (1974) abordam que uma realidade social é construída com base em estágios de interação social. Inicialmente, o indivíduo interage com sua família, escola, igreja e comunidade e quando passa a fazer parte de uma organização, será pressionado a assimilar a cultura organizacional.

É um pouco do enigma da esfinge: decifra-me ou te devoro. Há de se considerar que as organizações, além de produzirem bens e serviços, também criam artefatos culturais, como rituais e cerimônias, que funcionam como balizadores do comportamento humano (SMIRCICH,1983). Srour (1998), discorre que 
apesar dos agentes individuais serem habitualmente tão diversos, acabam por assemelharem-se em ritmos e jeitos, com uma tendência a serem conduzidos pelo racionalismo funcional, fruto das práticas institucionalizadas.

Esta abordagem não considera que o empregado terá sua cultura totalmente remodelada pela cultura organizacional, em uma espécie de lavagem cerebral, pois estará presente nele resquícios de sua formação social de primeira ordem, anterior ao ingresso na corporação. Mas o fato é que, para sobreviver em um mundo que tem formas e práticas institucionalizadas, haverá a necessidade de incorporar a cultura organizacional. Sendo assim, mesmo que individualmente o trabalhador possa discordar de alguma prática estabelecida, tenderá a aceitar o que a maioria entende como "dado como certo" na organização (SUCHMAN, 1995; THORNTON et al., 2013; SCOTT, 2013).

Nesse sentido, a cultura organizacional está fortemente vinculada à identidade da organização e é concebida como um conjunto de valores e pressupostos básicos expressos em elementos simbólicos que trazem uma certa estabilidade emocional (FLEURY; FISCHER, 1998). Assim, as organizações valem-se de tecnologias, normas, ritos e cerimônias para supostamente aumentar a previsibilidade do futuro (CALDAS; WOOD JR., 1997) e está conectada com outros elementos que influenciam ou são influenciados pela cultura, como estratégia, estrutura, sistema de recompensas e habilidades e competências desejadas (FREITAS, 1991).

Com isso, a cultura organizacional gera uma personalidade coletiva e quando bem gerenciada oferece um sentimento de pertença a um grupo de indivíduos que trabalham em uma mesma organização, propiciando o compartilhamento de significados e gerando um senso comum sobre como as coisas devem ser interpretadas e realizadas (MARTIN, 1992).

\section{Dimensões culturais de Hofstede}

A publicação da obra Culture's Consequences (HOFSTEDE, 1980) provocou manifestações de críticas e rejeições, mas também de entusiasmo, tal como costuma ocorrer quando do surgimento de novos paradigmas. As tipologias propostas por Hofstede $(1991,2001)$ - distância do poder, aversão à incerteza, individualidade versus coletividade e masculinidade versus feminilidade - inspiraram uma série de outros estudos em dimensões das culturas nacionais, muitos deles sugerindo a ampliação do número de dimensões (TROMPENAARS, 1993; KIM et al., 1994; TRIANDIS, 1995; TRIANDIS, 2004; HOUSE et al., 2004; MINKOV, 2011).

Apesar da série de trabalhos sugerindo a ampliação do número de dimensões, Hofstede (2011) manteve-se firme com a restrição à quantidade de tipologias, fundamentando-se no ponto de vista de Miller (1956), que defende que as classificações úteis não devem ter mais do que sete categorias, pois a mente humana tem uma capacidade limitada de processamento de informações.

Isso não significa que Hofstede tenha estagnado suas pesquisas e publicações sobre as dimensões culturais. Ao suspeitar de que os dados da IBM poderiam ter implicações para além desta corporação, realizou uma série testes, com as mesmas perguntas, para cerca de 400 estagiários de gestão de 30 países, em um programa internacional relacionado com a IBM. As médias por país foram significativamente correlacionadas com os escores obtidos no banco de dados da primeira pesquisa na IBM (HOFSTEDE, 2011). 
Encorajado pelos resultados da correlação de nível nacional, Hofstede (2011) realizou análise de fatores com dados em níveis mais elevados de agregação. Usando um fator de análise de uma matriz de 32 questões de valores para 40 países, encontrou problemas comuns com os quais os funcionários da IBM em todas essas sociedades tiveram de lidar, e o maio achado da pesquisa foi que as soluções para os problemas apresentaram perfis diferentes conforme o país de análise.

Não obstante Hofstede tenha aumentado as tipologias das dimensões culturais de quatro dimensões para seis, para efeito deste trabalho serão utilizadas as quatro dimensões dos trabalhos seminais de Hofstede (1980, 1991): distância hierárquica, individualismo versus coletivismo, masculino versus feminino e controle da incerteza.

O índice de distância hierárquica (IDH) aborda até que ponto os membros menos poderosos de instituições e organizações de um país esperam e aceitam que o poder seja distribuído de forma desigual, o que traz à tona o funcionamento das relações de dependência (HOFSTEDE, 1991, 2001). Hofstede (1991, 2001) descreveu uma sociedade que possui elevado índice de distância hierárquica como sendo favorável à existência de desigualdade entre pessoas, de forma que fique bem evidenciado que aqueles que têm menos poder devem depender dos que têm mais poder. Nesse sentido, existe uma tendência à centralização e os funcionários esperam que o gestor diga, exatamente, o que deve ser feito, fato que denota pouco anseio por autonomia.

Em sociedades com pequena distância hierárquica, as desigualdades entre as pessoas são mitigadas, o que favorece a interdependência entre os que detêm mais poder e os que têm menos poder. Nesse caso, em relação às organizações, os funcionários gostam de ser consultados sobre as decisões que serão tomadas, o que gera uma estrutura mais descentralizada, com baixa dependência dos funcionários em relação à chefia (HOFSTEDE, 1991, 2001).

Em contrapartida, nos países onde o índice é elevado a relação se inverte. Conforme Hofstede (1991, p. 42), há uma dependência considerável dos funcionários em relação a seus chefes, com "uma grande lacuna emocional entre chefia e subordinados, os quais raramente contradizem suas chefias explicitamente".

A segunda dimensão diz respeito ao índice de individualismo versus coletivismo (IDV); o individualismo está relacionado à preferência por um estilo vida sem muitas amarras sociais, em contrapartida, o coletivismo se manifesta quando prevalecem os interesses do grupo. Estes conceitos são bastante úteis para explicar como a influência cultural impacta a dinâmica organizacional e o desenvolvimento de tarefas em locais de trabalho.

Esta dimensão considera o nível de integração das pessoas em grupos de uma sociedade. Nas culturas onde há prevalência do individualismo, os laços entre os indivíduos são soltos. Ao contrário, nas culturas com ênfase coletivista, as pessoas, desde o nascimento, estão fortemente integradas, coesas, e as famílias continuam protegendo-se em troca de inquestionável lealdade (HOFSTEDE, 2011).

Segundo Hofstede et al. (2010), o índice Individualismo tende a prevalecer nos países desenvolvidos e ocidentais, enquanto o coletivismo prevalece em países menos desenvolvidos e orientais; o Japão assume uma posição intermediária em relação a essa dimensão.

A terceira dimensão é o índice Masculinidade versus Feminilidade (MAS); Hofstede (1991) emprega os adjetivos masculino e feminino em um sentido relativo. Na composição deste índice, admite-se que um homem pode se comportar de maneira feminina e uma mulher, de forma masculina. Esta questão é abordada 
sob o aspecto comportamental, e os comportamentos masculinos e femininos são diferentes tanto nas sociedades tradicionais como nas sociedades modernas. Independentemente do tipo de sociedade, há uma convergência marcante dentro do que se espera como comportamento masculino, ligado à firmeza, à competição e ao rigor, em contrapartida do que se espera como comportamento feminino, caracterizado pela delicadeza, ternura e generosidade (HOFSTEDE, 1991).

Hofstede (1991) descreveu uma sociedade que possui elevado índice de masculinidade como sendo favorável à existência de trabalhos que valorizam o sucesso e o progresso material, em ambientes que enfatizam a competição entre colegas e conflitos resolvidos por meio de confrontos. Sociedades que prezam o polo masculino têm simpatia pelos mais fortes e dão muita importância às coisas materiais.

Nas sociedades com características de feminilidade, existe um forte apelo à construção de relações calorosas e valoriza-se a igualdade, a solidariedade e a qualidade de vida no trabalho. Os conflitos são resolvidos por meio de negociação e se dá muito mais importância às pessoas do que às coisas materiais (HOFSTEDE, 1991).

Conforme Hofstede et al. (2010), o Índice de masculinidade versus feminilidade apresenta-se alto no Japão, nos países de língua alemã e em alguns países latinos, como Itália e México; é moderadamente alto em países de língua inglesa e nos países ocidentais; é baixo em países nórdicos e na Holanda; e moderadamente baixo em alguns países latinos e asiáticos, como França, Espanha, Portugal, Chile, Coréia e Tailândia, que tendem mais para as características de feminilidade.

A quarta dimensão passa pelo índice de controle de incerteza (ICI). De acordo com Hofstede (1991), seres humanos, naturalmente, sofrem ansiedade por não saber como será o dia de amanhã. O futuro é incerto e esta dimensão mede o grau de inquietude dos habitantes em relação a situações desconhecidas.

Culturas que evitam a incerteza tentam minimizar a possibilidade de tais situações por meio de rigorosos códigos de comportamento, leis, regras e desaprovação de opiniões divergentes (HOFSTEDE, 2011). O tipo oposto, ou seja, as culturas com baixa aversão à incerteza, são mais tolerantes com as opiniões divergentes, tentam ter menos regras e, no aspecto filosófico e religioso, são empiristas, relativistas e permitem que diferentes correntes fluam lado a lado. As pessoas pertencentes a essas culturas são mais fleumáticas e contemplativas (HOFSTEDE et al. 2010).

Hofstede (2011) aponta que o índice de aversão à incerteza tende a ser maior no Oriente, em países da Europa Central, nos países latinos, no Japão e em países de língua alemã; e menor nos países de língua inglesa, nórdicos e de cultura chinesa.

\section{METODOLOGIA}

Este trabalho é um programa de pesquisa progressista, amparado em abordagens contemporâneas na temática da cultura organizacional, e que busca preservar o que foi construído pela teoria desde os autores seminais. Parte do princípio de que o progresso da ciência é cumulativo, isto é, com o desenvolvimento das investigações, vão sendo formuladas teorias cada vez mais abrangentes, dotadas de maior poder explicativo e preditivo (ALVEZ-MAZZOTTI; GEWANDSZNAJDER, 2001).

O propósito deste trabalho foi identificar as semelhanças e as diferenças entre as dimensões culturais fornecidas pelos índices de Hofstede observadas em funcionários de uma empresa brasileira da área de 
agronegócio (cooperativa), um hospital e um banco comercial e a pesquisa desenvolvida por Hofstede (1980, 1991) nas unidades da IBM, em 53 países, na década de 1970.

O método de pesquisa utilizado neste estudo teórico-empírico foi o descritivo, no qual os fatos são observados, registrados, analisados, classificados e interpretados, sem interferência do pesquisador, e valeuse de fontes secundárias, na medida em que foram utilizadas contribuições já publicadas sobre o tema estudado (GODOI et al., 2007). Neste estudo, os dados foram coletados de três dissertações sobre as dimensões de Hofstede.

O banco pesquisado (FERREIRA, 2008) enquadra-se como de varejo, sob a forma de sociedade de economia mista, na qual o governo federal detém $51 \%$ das ações. A empresa opera em todo o Brasil e em alguns países, contando em seu efetivo com 82,5 mil funcionários. As agências onde foram aplicadas as pesquisas se encontram no Vale do Itajaí e oeste paranaense.

O hospital pesquisado (PALMEIRA, 2010) foi criado em 1920 pela comunidade Luterana, possui aproximadamente 150 leitos, realiza cerca de 900 internações por mês e 3.900 atendimentos no Pronto Atendimento. $\mathrm{O}$ foco da atividade se direciona para especialidades de alta complexidade, com 319 médicos atuantes no Corpo Clínico que compõem 57 especialidades e 508 profissionais de outras áreas, como enfermeiros, psicólogos, farmacêuticos, Administradores e técnicos.

A cooperativa agrícola pesquisada (CASAGRANDE, 2009) atua na produção agropecuária com atuação no Paraná, Santa Catarina, Mato Grosso, Mato Grosso do Sul e Paraguai. A organização possui 46 unidades de recebimento de produção e suas atividades concentram-se no segmento agroindustrial. Destaca-se a produção de soja, milho, trigo, mandioca, leite e suínos, além da atuação na prestação de serviços para produtores rurais. A população foi composta pelos funcionários de uma cooperativa agrícola, compreendendo a sua unidade administrativa no Brasil, localizada em Palotina-PR, que possui 74 funcionários, e sua unidade paraguaia, localizada em Katuetê, com 35 funcionários.

\section{RESULTADOS DA PESQUISA}

Esta seção apresenta a análise dos dados, obtidos por meio da aplicação do questionário de Hofstede (2001), em uma cooperativa agrícola, um banco e um hospital, e a análise das respostas que mensuram as quatro dimensões em estudo.

\section{Índice distância hierárquica}

Os índices desta dimensão foram apurados por meio da contagem média da frequência absoluta das respostas e da soma de porcentagens de respostas, de acordo com a seguinte fórmula:

$\mathrm{IDH}=135-25 \times$ (contagem média da afirmativa 01) + (soma das porcentagens das respostas 1 e 2 da afirmativa 34$)$ - (porcentagens das respostas 3 , da afirmativa 35), conforme Tabela 1. 
Tabela 1 - Aplicação da fórmula de Hofstede (2001) do IDH - Índice de Distância Hierárquica

\begin{tabular}{l|l|l|c}
\hline \multicolumn{1}{c|}{ Cooperativa Agrícola } & \multicolumn{1}{|c|}{ Banco } & \multicolumn{1}{|c}{ Hospital } & \multicolumn{1}{|c}{$\begin{array}{c}\text { Brasil (IBM) } \\
\text { Hofstede (2001) }\end{array}$} \\
\hline $\mathrm{IDH}=135(-) 25(\mathrm{x}) 3,03(+)$ & $\mathrm{IDH}=135(-) 25(\mathrm{x})$ & $\mathrm{IDH}=135(-) 25(\mathrm{x})$ & \\
$42,85(-) 17,14=\mathbf{8 4 , 9 6}$ & $\begin{array}{l}3,03 \\
\end{array}$ & $\begin{array}{l}(+) 9,97 \\
(+)\end{array}$ & $\mathbf{6 9}(-) 37,50=$ \\
& $\mathbf{3 1 , 1 3}$ & & \\
\hline
\end{tabular}

Fonte: Hofstede (2001) e dados da pesquisa.

Numa escala de 0 (zero) a 100 (cem), na qual 100 representa alta concentração de poder, observase que a pesquisa de Hofstede (1991) apresentou o Brasil (IBM) com índice elevado de IDH, ou seja, 69, ficando próximo aos patamares observados em países como Hong Kong, França, Colômbia, Salvador, Turquia e Bélgica. Os dados coletados na cooperativa agrícola apresentaram índice fortemente elevado, com 84,96, patamar parecido com o apresentado por países como México, Venezuela e países árabes. Já as pesquisas realizadas no Banco e no Hospital apresentaram baixo IDH, 31,13 e 24,75, respectivamente. $O$ Banco ficou em um patamar equivalente ao de países como Noruega, Suécia, Finlândia e Suíça, enquanto o Hospital ficou muito próximo dos países com os mais baixos índices de distância hierárquica da pesquisa de Hofstede (1991, 2001), como Nova Zelândia, Dinamarca, Israel e Áustria.

Essa situação sinaliza que a pesquisa de Hofstede (1991, 2001), realizada no Brasil (IBM), apontou uma tendência para ambientes em que há grande dependência dos subordinados perante os chefes, seja ela de boa-vontade ou não; as desigualdades são aceitas e, até mesmo, valorizadas, ou seja, acredita-se que quem tem menos poder deve depender de quem tem mais. Nesse tipo de organização, superiores e subordinados consideram-se desiguais por natureza e a gestão costuma ser centralizada. Os subordinados desejam um chefe com perfil autocrata e benevolente, e a maioria espera que os chefes lhes digam o que fazer, o que elimina a criatividade dos grupos de trabalho (HOFSTEDE, 1991, 2001). Esta mesma análise é válida para a Cooperativa Agrícola pesquisada, só que com mais ênfase ainda, uma vez que a organização pesquisada apresentou índices semelhantes aos de países com maior distância hierarquia, nos estudos de Hofstede $(1991,2001)$

De acordo com a teoria das dimensões de Hofstede (1991, 2001), os resultados obtidos no Banco e no Hospital, 31 e 25, respectivamente, demonstram que estas são organizações onde as desigualdades entre as pessoas tendem a ser minimizadas, pois existe certa interdependência entre quem tem mais poder e quem tem menos. A hierarquia dessas organizações pressupõe desigualdade de papéis e descentralização. Os subordinados esperam ser consultados sobre as decisões que serão tomadas, os privilégios e símbolos de status são mal vistos e o chefe ideal é um democrata competente.

Ficou evidenciada, na análise do IDH, uma grande distorção entre os índices de dois setores distintos, dentro de um mesmo país. A Cooperativa Agrícola apontou índice de intensa distância hierárquica, enquanto o Hospital apresentou índice semelhante aos menores índices observados em todos os países estudados por Hofstede (1991, 2001). 


\section{Índice individualismo versus coletivismo}

Os índices desta dimensão foram apurados por meio da contagem média da frequência absoluta das respostas, de acordo com a seguinte fórmula:

IDV $=(-) 27 \times($ contagem média da afirmativa 07) $+30 \times$ (contagem média da afirmativa 09) + $76 \times$ (contagem média da afirmativa 13) - $43 \times$ (contagem média da questão 19) - 29, conforme Tabela 2.

Tabela 2 - Aplicação da fórmula de Hofstede (2001) do IDV - Índice de Individualismos versus Coletivismo

\begin{tabular}{c|c|c|c}
\hline Cooperativa Agrícola & Banco & Hospital & $\begin{array}{c}\text { Brasil (IBM) } \\
\text { Hofstede (2001) }\end{array}$ \\
\hline IDV = (-) $27(\mathrm{x}) 1,43(+)$ & IDV $=(-) 27(\mathrm{x}) 1,09(+)$ & IDV $=(-) 27(\mathbf{x}) 1,36(+)$ & \\
30 & 30 & 30 & $\mathbf{3 8}$ \\
$(\mathrm{x}) 1,40(+) 76(\mathrm{x}) 1,51(-)$ & $(\mathrm{x}) 1,19(+) 76(\mathrm{x}) 1,41(-)$ & $(\mathrm{x}) 1,33(+) 76(\mathrm{x}) 1,75(-)$ & \\
43 & 43 & $(x) 1,70-29=\mathbf{3 4 , 0 8}$ & \\
(x) $1,66-29=\mathbf{1 7 , 7 7}$ & (x) $1,25-29=\mathbf{3 0 , 6 8}$ & (x) 13 & \\
\hline
\end{tabular}

Fonte: Hofstede (2001) e dados da pesquisa.

Numa escala de 0 (zero) a 100 (cem), na qual 100 representa alto índice de individualismo (HOFSTEDE, 1991, 2001), observa-se que a pesquisa realizada por Hofstede $(1991,2001)$ apresentou o Brasil (IBM) como cultura coletivista intermediária, com índice 38, patamar próximo ao observado em países como a Jamaica, a Turquia e países árabes. Índices semelhantes foram observados nas pesquisas realizadas no Banco e no Hospital, com 30,68 e 34,08, respectivamente. Os resultados gerados no Banco ficaram próximos aos apresentados por países como México e Filipinas; e no Hospital, próximos aos observados na Grécia e no Uruguai. Já na pesquisa realizada na cooperativa agrícola, o índice de 17,77 demonstra uma organização fortemente coletivista, numa classificação próxima à dos países mais coletivistas da pesquisa de Hofstede (1991, 2001), como Coréia do Sul, Taiwan, Peru, Costa Rica, Paquistão, Indonésia, Colômbia, Venezuela, Panamá, Equador e Guatemala.

A teoria de Hofstede $(1991,2001)$ indica que nas organizações coletivistas há uma dependência emocional entre os membros de uma organização. Numa cultura coletivista, o empresário precisa sempre ter em mente que não contrata um indivíduo, mas uma pessoa que pertence a um grupo. Neste caso, o trabalhador atuará de acordo com os interesses do grupo, mesmo que estes não coincidam com suas pretensões pessoais. Para motivar os membros, nesse tipo de organização, as empresas adotam estratégias como antecipação do pagamento e de premiações, formação de grupos de trabalho e compartilhamento de resultados, pois os colaboradores sentem-se mais produtivos quando trabalham em equipe do que individualmente. Nas sociedades coletivistas, o desempenho deficiente de um funcionário não, necessariamente, motiva sua demissão, pois existem fortes amarras morais entre o empregador e o empregado, como num vínculo familiar. Na administração, a relação prevalece sobre a tarefa e sobre o vínculo profissional; em termos morais, o ambiente é, praticamente, familiar (HOFSTEDE, 1991, 2001). 
Índice masculinidade versus feminilidade

Os índices desta dimensão foram apurados por meio da contagem média da frequência absoluta das respostas, de acordo com a seguinte fórmula:

MAS $=-66 \times($ contagem média da afirmativa 08) $+60 \times($ contagem média da afirmativa 09) $+30 \times($ contagem média da afirmativa 15) - 39 x (contagem média da questão 16) + 76, conforme Tabela 3.

Tabela 3 - Aplicação da fórmula de Hofstede (2001) do MAS - Índice de Masculinidade versus Feminilidade

\begin{tabular}{c|c|c|c}
\hline Cooperativa Agrícola & Banco & Hospital & $\begin{array}{c}\text { Brasil (IBM) } \\
\text { Hofstede (2001) }\end{array}$ \\
\hline MAS = (-) $66(\mathrm{x}) 1,66(+)$ & MAS = (-) $66(\mathrm{x}) 1,53(+)$ & MAS = (-) $66(\mathrm{x}) 1,88(+)$ & \\
$60(\mathrm{x}) 1,40(+) 30(\mathrm{x}) 1,71$ & 60 & $60(\mathrm{x}) 1,33(+) 30(\mathrm{x})$ & $\mathbf{4 9}$ \\
$(-) 39$ & $(\mathrm{x}) 1,19(+) 30(\mathrm{x}) 1,16(-)$ & 1,76 & \\
$(\mathrm{x}) 1,76(+) 76=\mathbf{3 3 , 0 6}$ & 39 & $(-) 39(\mathrm{x}) 1,82+76=$ & \\
& $(\mathrm{x}) 1,41(+) 76=\mathbf{2 6 , 2 3}$ & $\mathbf{1 3 , 5 4}$ & \\
\hline
\end{tabular}

Fonte: Hofstede (2001) e dados da pesquisa.

Numa escala de 0 (zero) a 100 (cem), na qual 100 representa alto índice de masculinidade, observase que a pesquisa de Hofstede $(1991,2001)$ apresentou o Brasil (IBM) com característica intermediária entre a masculinidade e a feminilidade, com índice 49, próximo aos patamares observados em países como Malásia, Paquistão, Cingapura e Israel. Os dados coletados na Cooperativa Agrícola e no Banco apresentaram uma tendência para a feminilidade, com índices de 33,06 e 26,23, respectivamente, próximos aos observados em países como Finlândia, Chile e Portugal. Já o índice observado no Hospital mostrou que essa instituição é intensamente feminina, com índice de 13,54, o que o coloca em patamar semelhante ao de países com os mais baixos índices MAS da pesquisa de Hofstede (1991, 2001), como Holanda, Noruega e Suécia.

Conforme Hofstede (2001, p. 119), nas sociedades femininas, não existe um culto ao brilhante, ao "fora de série", pois a tônica é mais para a modéstia, o que propicia o desenvolvimento de um espírito de solidariedade, devido à competição não ser tão intensa. A escolha da profissão é decorrente do interesse do estudante por um domínio em particular. Em sociedades femininas, existe uma maior preocupação com a qualidade de vida, valoriza-se a igualdade e o perfil de chefia aproxima-se da linha conciliadora, onde as decisões são tomadas com base em discussões em grupo. Assim, os conflitos são resolvidos por meio de negociação e compromisso. Finalmente, pesquisas mostraram que as sociedades femininas dão grande importância às pessoas, valorizam relações calorosas e prezam os objetivos sociais, como relacionamentos, ajuda ao próximo e preservação do meio ambiente. 


\section{Índice de Controle da Incerteza}

Os índices desta dimensão foram apurados por meio da contagem média da frequência absoluta das respostas e da soma de porcentagens de respostas, de acordo com a seguinte fórmula:

$\mathrm{ICl}=300-30 \times$ (contagem média da afirmativa 60) - (porcentagem da intenção de ficar menos que 5 anos na empresa, afirmativa 65) - 40 x (contagem média da afirmativa 67), conforme Tabela 4.

Tabela 4 - Aplicação da fórmula de Hofstede (2001) do ICI - Índice de Controle da Incerteza

\begin{tabular}{c|c|c|c}
\hline Cooperativa Agrícola & Banco & Hospital & $\begin{array}{c}\text { Brasil (IBM) } \\
\text { Hofstede (2001) }\end{array}$ \\
\hline $\mathrm{ICI}=300(-) 30(\mathrm{x}) 2,66(-)$ & $\mathrm{ICI}=300(-) 30(\mathrm{x}) 2,50(-)$ & $\mathrm{ICI}=300(-) 30(\mathrm{x}) 2,27(-)$ & $\mathbf{7 6}$ \\
$15,15(-) 40(\mathrm{x}) 2,97=$ & $18,75(-) 40(\mathrm{x}) 2,94=$ & $10,45(-) 40(\mathrm{x}) 3,07=$ & \\
$\mathbf{8 6 , 2 5}$ & $\mathbf{8 8 , 6 5}$ & $\mathbf{9 8 , 6 5}$ & \\
\hline
\end{tabular}

Fonte: Hofstede (2001) e dados da pesquisa.

Numa escala de 0 (zero) a 100 (cem), na qual 100 representa alto índice de aversão à incerteza, observa-se, na unidade brasileira, uma característica muito forte vinculada ao controle da incerteza, com índice 86,25. A unidade paraguaia também apresenta um elevado índice de aversão à incerteza, ou seja, 79,27, o que representa um considerável viés em direção a esse tipo de comportamento.

Numa escala de 0 (zero) a 100 (cem), na qual 100 representa alto índice de masculinidade, observase que a pesquisa de Hofstede $(1991,2001)$ constatou que o Brasil (IBM) apresenta elevado índice de controle da incerteza, isto é, 76 , ficando próximo aos patamares encontrados em países como Itália e Venezuela. Os dados levantados da Cooperativa Agrícola e do Banco apresentaram um viés ainda mais elevado de controle da incerteza, com índices de 86 e 88, respectivamente, próximos aos observados em países como a extinta lugoslávia, França, Chile, Espanha, Peru, Costa Rica, Panamá e Argentina. Já o índice observado no Hospital mostrou que, nessa instituição, o controle da incerteza é muito intenso, com índice 99, o que a coloca em patamar semelhante ao de países com o mais alto índice $\mathrm{ICl}$, conforme pesquisa de Hofstede (1991, 2001), como Uruguai, Guatemala, Portugal e Grécia.

Conforme Hofstede (1991, 2001), em países com elevado índice de controle de incertezas, no local de trabalho existem numerosas leis, formais e informais, que controlam as obrigações e os direitos de empregadores e assalariados. Há uma predisposição para a busca de precisão e pontualidade, e a incerteza é percebida como grande ameaça, o que provoca sentimento de ansiedade. Com isso, "o diferente" é interpretado como perigoso, há necessidade emocional de regras, mesmo que sejam desnecessárias, e intolerância a comportamentos não-convencionais, o que impacta negativamente as inovações e faz com que os indivíduos sejam compelidos a "trabalhar duro" e constantemente.

Finalizando, a Tabela 5 apresenta um comparativo dos resultados das quatro dimensões, entre os índices encontrados por Hofstede $(1991,2001)$ para o Brasil (IBM), em 1973, e os dados obtidos pela pesquisa realizada em uma Cooperativa Agrícola, em um Banco e um Hospital. 
Os resultados sugerem que a cultura organizacional caracterizada em diferentes áreas de atuação profissional pode configurar-se como fator mais determinante do que a cultura nacional, na interpretação das dimensões culturais envolvidas.

Tabela 5 - Comparativo dos resultados das dimensões entre o Brasil na pesquisa de Hofstede (2001) e as unidades da Cooperativa Agrícola, do Banco e do Hospital

\begin{tabular}{l|c|c|c|c}
\hline Dimensões Culturais & Brasil (Hofstede) & Cooperativa Agrícola & Banco & Hospital \\
\hline Distância Hierárquica & 69 & 85 & 31 & 25 \\
Individualismo versus & 38 & 18 & 31 & 34 \\
coletivismo & 49 & 33 & 26 & 14 \\
Masculinidade versus & 76 & 86 & 89 & 99 \\
feminilidade & Aversão à incerteza &
\end{tabular}

Fonte: Hofstede (2001) e dados da pesquisa.

\section{CONSIDERAÇÕES FINAIS}

Os resultados desta pesquisa demonstram contrastes em relação ao trabalho de Hofstede (1991, 2001), que apontou na dimensão Distância Hierárquica, para o Brasil, índice 76, e a presente pesquisa apresentou 25 para hospital e 31 para o banco. A dimensão Masculinidade versus Feminilidade aparece com índice 49 no estudo de Hofstede $(1991,2001)$, e nesta pesquisa índice 14 para o hospital. Na dimensão Individualismo versus Coletivismo, enquanto, na pesquisa de Hofstede (1991, 2001), o Brasil ficou enquadrado com 38, esta pesquisa apontou índice 18 para a cooperativa, ou seja, igual ao de países com maior coletividade, pela pesquisa de Hofstede (2001). Finalmente, em relação à dimensão Aversão à Incerteza, enquanto o Brasil ficou com índice 76, o hospital apresentou índice quase máximo, com índice 99.

Entende-se que essas discrepâncias encontradas em relação à pesquisa realizada por Hofstede na IBM e os achados nas três empresas objetos desta pesquisa ocorrem por uma negligência ao impacto da cultura organizacional na análise. Em se tratando de uma abordagem sobre comportamento organizacional, há que se considerar a interação humana no ambiente interno da corporação e exige uma visão interdisciplinar na análise para que seja possível identificar a dinâmica de como as pessoas e grupos se comportam e se relacionam e, também, como os indivíduos e grupos interagem com a própria organização da qual fazem parte (JOHANN, 2013).

Nesse sentido, as organizações atuam como geradoras de cultura, graças ao compartilhamento de experiências que afloram no seu ambiente, que envolve o que os funcionários trazem consigo de sua socialização primária (família, escola, igreja, comunidade) e socialização secundária, que é afetada pela cultura institucionalizada da organização (BERGER E LUCKMANN, 1974).

A partir do momento que no ambiente organizacional os indivíduos passam a compartilhar uma cultura, a partir do estabelecimento de um senso comum na forma de interpretar e realizar as coisas, há uma tendência de que a cultura organizacional caracterize as corporações, objetificando o "dado como certo" e gerando modelos mentais catalisadores da institucionalização de formas e práticas (THORNTON et al. 2013; SCOTT, 2013). Esse entendimento coletivo pode ser obtido por determinadas práticas como processos de 
seleção, formas de avaliação dos desempenhos, treinamentos oferecidos e até mesmo regras de desempate em promoções (MARTIN, 1992).

Sendo assim, os resultados deste trabalho sugerem que, na medida em que cultura organizacional pode ser modelada em função de fatores como tipo de organização, tipo da atividade desenvolvida e perfil dos profissionais, precisa ser considerada de forma complementar à cultura nacional no estabelecimento das dimensões culturais de Hofstede (1980, 1991, 2001).

Como limitação de pesquisa, considera-se o número de empresas pesquisadas e espera-se que este trabalho instigue à realização de novos trabalhos em distintos tipos de organizações, para que se possa comparar os resultados levantados com as dimensões da cultura nacional de Hofstede $(1991,2001)$.

\section{REFERÊNCIAS}

ALVES-MAZOTTI, A. J.; GEWANDSZNAJDER, F. O método nas ciências naturais e sociais: pesquisa quantitativa e qualitativa. São Paulo: Pioneira, 1998.

BECKER, Howard S. Culture: A Sociological View. Yale Review, v. 71, n. 4, p. 513-527, 1982.

BERGER, P. L.; LUCKMANN, T. A construção social da realidade: tratado de sociologia do conhecimento. Petrópolis: Vozes, 1974

CALDAS, M. P.; WOOD JR, T. Identidade organizacional. Revista de Administração de Empresas, v. 37, n. 1, p. 6-17, 1997.

CASAGRANDE, R.M. Dimensões da Cultura Organizacional no Modelo de Hofstede: Estudo em uma Empresa Brasileira Internacionalizada. Dissertação (Mestrado em Administração) - Fundação Universidade de Blumenau, 2009.

FERREIRA, A.C. Dimensões da Cultura Organizacional no Modelo de Hofstede: Estudo em Agências do Paraná e Santa Catarina de uma Instituição Financeira. Dissertação (Mestrado em Administração) - Fundação Universidade Regional de Blumenau, 2008.

FLEURY, M. T. L. FISCHER, R. M. Gestão de pessoas: os desafios de aproximar a teoria da prática e vice-versa. Revista de Administração da Universidade de São Paulo, v. 33, n. 2, 1998.

GODOI, C. K.; BANDEIRA-DE-MELLO, R.; SILVA, A. B. da. Pesquisa qualitativa em estudos organizacionais: paradigmas, estratégias e métodos. São Paulo: Saraiva, 2007.

HOFSTEDE, G. Culture's Consequences: International Differences in Work-Related Values. Beverly Hills, CA: Sage. 1980.

HOFSTEDE, G. Cultures and Organizations: Software of the Mind. London, UK: McGraw-Hill. 1991.

HOFSTEDE, G. Culture's Consequences: Comparing Values, Behaviors, Institutions and Organizations across Nations. Thousand Oaks, CA: Sage. 2001.

HOFSTEDE, G. The GLOBE debate: Back to relevance. Journal of International Business Studies, v.41, p.1339-46. 2010.

HOFSTEDE, G. Dimensionalizing Cultures: The Hofstede model in context. Online Readings in Psychology and Culture, Unidade 2, 2011.

HOFSTEDE, G., HOFSTEDE, G. J.; MINKOV, M. Cultures and Organizations: Software of the Mind. New York: McGraw-Hill. 2010.

HOUSE, R. J., HANGES, P. J., JAVIDAN, M., DORFMAN, P. W.; GUPTA, V. Culture, leadership, and organizations: The GLOBE study of 62 societies. Thousand Oaks, CA: Sage. 2004.

JOHANN, S. L. Gestão da cultura corporativa: como as organizações de alto desempenho gerenciam sua cultura organizacional. São Paulo: Saraiva, 2004.

JOHANN, S. Comportamento organizacional: teoria e prática, $1^{\text {a }}$ ed. São Paulo: Saraiva, 2013.

KIM, U, TRIANDIS, H. C., KAGITGIBASI, C., CHOI, S. C., YOON, G. Individualism and collectivism: Theory, method and applications. Thousand Oaks, CA: Sage. 1994.

MARTIN, J. Cultures in organizations: three perspectives. New York: Oxford University Press, 1992.

MILLER, G. A. The magical number seven, plus or minus two: Some limits on our capacity for processing information. Psychological Review, v.63, p.81-97, 1956. 
MINKOV, M. Cultural differences in a globalizing world. Bingley, UK: Emerald, 2011.

MORGAN, G. Imagens da Organização. São Paulo: Atlas, 1996.

O'REILLY, C. A.; CHATMAN, J.; CALDWELL, D. F. People and organizational culture: A profile comparison approach to assessing person-organization fit. Academy of Management Journal, v. 34, n. 3, p. 487-516, 1991.

PALMEIRA, E. D. S. Cultura Organizacional: Estudo em uma Organização Hospitalar. Dissertação (Mestrado em Administração) - Fundação Universidade Regional de Blumenau, 2010.

ROBBINS, S.P. Comportamento Organizacional. Rio de Janeiro: LTC Editora, $8^{a}$ ed. 2002.

SCHEIN, E.H. Organizational culture and leadership: a dynamic view, Jossey-Bass, San Francisco, CA, 1985.

SCOTT, W. Richard. Institutions and organizations: Ideas, interests, and identities. Sage Publications, 2013.

SCOTT, R. W.; CHRISTENSEN, S. The institutional construction of organizations: international and longitudinal studies. Sage Publications, 1995.

SELZNICK, P. Foundations of the Theory of Organization. American Sociological Review, p. 25-35, 1948.

SMIRCICH, L. Concepts of Culture and Organizational Analysis. Administrative Science Quarterly, v. 28, n.3, p. 339358, 1983.

SROUR, R. H. Poder, cultura e ética nas organizações. Rio de Janeiro: Campus, 1998.

SUCHMAN, M. C. Managing legitimacy: Strategic and institutional approaches. Academy of management review, v. 20, n. 3, p. 571-610, 1995.

THORNTON, P. H.; OCASIO, W.; LOUNSBURY, M. The institutional logics perspective: a new approach to culture, structure, and process. Oxford. 2013.

TRIANDIS, H. C. Individualism and Collectivism. Boulder, CO: Westview, 1995.

TRIANDIS, H. C. The many dimensions of culture. Academy of Management Executive, v.18, p.88-93, 2004.

TROMPENAARS, F. Riding the Waves of Culture: Understanding Cultural Diversity in Business. London, UK: Economist Books, 1993.

WREN, D.A. Ideias de administração: o pensamento moderno. São Paulo: Ática, 2007. 